\title{
'They say we are crèche teachers': Experiences of pre-service mathematics teachers taught through the medium of isizulu
}

\author{
Authors: \\ Linda van Laren \\ Busisiwe Goba ${ }^{1}$

\section{Affiliations:} \\ ${ }^{1}$ Department of Mathematics \\ Education, University of \\ KwaZulu-Natal, South Africa \\ Correspondence to: \\ Busisiwe Goba \\ Email: \\ gobab@ukzn.ac.za \\ Postal address: \\ Private Bag X03, Ashwood \\ 3605, South Africa \\ Dates: \\ Received: 14 Feb. 2013 \\ Accepted: 12 May 2013 \\ Published: 12 June 2013 \\ How to cite this article: \\ Van Laren, L., \& Goba, B. \\ (2013). 'They say we are \\ crèche teachers': Experiences \\ of pre-service mathematics \\ teachers taught through \\ the medium of isizulu. \\ Pythagoras, 34(1), Art. \\ \#216, 8 pages. http://dx.doi. \\ org/10.4102/pythagoras. \\ v34i1.216

\section{Copyright:} \\ (C) 2013. The Authors. \\ Licensee: AOSIS \\ OpenJournals. This work \\ is licensed under the \\ Creative Commons \\ Attribution License.
}

Read online:
Language of instruction, both in schools and higher education institutions (HEIs), is a contentious issue in South Africa. At our university in the KwaZulu-Natal province of South Africa a language policy was approved in agreement with the Language Policy for Higher Education, recommending promotion of isiZulu as a medium of instruction for teaching and learning. In complying with this policy the School of Education of our university offered three education modules (Numeracy, Life Skills and Literacy) in the Foundation Phase (FP) Postgraduate Certificate in Education (PGCE) through the medium of isiZulu. Against this background we conducted a qualitative study with 16 FP PGCE pre-service teachers selected purposefully from the 2011 cohort who completed the FP numeracy education module in isiZulu. Participants were generally positive about their experiences of being taught in isiZulu, but highlighted challenges related to isiZulu as a medium of instruction for academic concept explanations, translation of teaching and learning materials, and the status of isiZulu as an instruction medium at a HEI.

\section{Introduction}

In post-apartheid South Africa the government actively promotes multilingualism. One vehicle through which multilingualism has been promoted is recognition of the 11 official languages in South Africa. Previously only English and Afrikaans were afforded higher status as mediums of instruction at higher education institutions (HEIs). However, the Languages in Education Policy (Department of Education [DOE], 1997) notes that schooling is to maintain home language(s), but it also mandates that access to and acquisition of additional language(s) should be provided. In addition, learners in the Foundation Phase (FP) (Grade R-3) are expected to learn all subjects in their mother tongue. Despite the good intentions of the Languages in Education Policy, there are complications with the issue of languages spoken in South Africa, especially in urban areas where there is mixing of different ethnic groups (Howie, 2002).

Higher education institutions are required to take cognisance of the Languages in Education Policy and expected to provide professional development for teachers in the FP using mother tongue instruction. Desai (2012) adds that:

the state will have to develop resources in these [African] languages, resources such as teachers trained to teach through the African mother tongue, textbooks, reading material and terminology lists. African languages are likely to be seen as viable choices as languages of learning and teaching if they have some currency in domains other than the private. (p. 58)

In keeping with the recommendations of the Language Policy for Higher Education (DOE, 2002), our university in the KwaZulu-Natal province of South Africa formulated a language policy which includes promotion of mother tongue instruction in modules within its colleges as well as the fostering of multilingualism (University of KwaZulu-Natal, 2006). The university's strategic plan (2007-2016) provides strategies and goals for implementing its policies, vision and mission. The strategic plan indicates that English will remain the primary academic language but that isiZulu should be developed as a medium of instruction. In addition, the strategic plan indicates that the promotion of isiZulu will be encouraged through appropriate resources (University of KwaZuluNatal, 2013).

Naturally, the School of Education at the university realigned its programme offerings to accommodate the new university-wide policy on language. Accordingly, since 2008 the FP Postgraduate Certificate in Education (PGCE) life skills and literacy education modules are offered in mother tongue (isiZulu) as well as in English. The numeracy education module was only offered for the first time in isiZulu in 2011 because of unavailability of materials in isiZulu and staff able to lecture in isiZulu. 
What does the literature say about mother tongue instruction in schools and higher education institutions? The literature points out that when young children learn in a second language, their academic progress is inhibited (Alexander, 2000, 2009; Cummins, 1981; Skutnabb-Kangas, 2009). In addition, the literature suggests that young children gain culturally, socially, linguistically and cognitively when they learn in their mother tongue (Alexander, 2009; Kajoro \& Halai, 2012; Mashiya, 2010, 2011). There is a dearth of literature about mother tongue instruction and teaching numeracy (mathematics) ${ }^{1}$ education modules (Green, Parker, Deacon \& Hall, 2011). Instead, the literature focuses mainly on the language of instruction in teaching numeracy and mathematics to school learners in multicultural contexts (Adler \& Setati, 2000; Setati, 2008). Furthermore, the literature usually considers proficiency in a language in relation to understanding of mathematics (Chen \& Li, 2008; Kajoro \& Halai, 2012). Researchers also highlight performance of English Second Language learners in mathematics (Essien, 2010), and the challenges these learners experience when learning mathematics in multilingual South African classrooms (Adler, 1998; Adler \& Setati, 2000; Setati, 1998, 2008; Vandeyar, 2010).

Globally, English is regarded as the dominant symbolic language necessary for access to and status in sociopolitical, economic and educational arenas (Mufanechiya \& Mufanechiya, 2011). Particularly in Africa, English is still regarded as the language of education and provides opportunities for economic and social upliftment (Kajoro \& Halai, 2012; Mufanechiya \& Mufanechiya, 2011; Setati, 2008). Researchers in mother tongue instruction argue that if learners, students and teachers are made to feel that their mother tongue is inferior and 'is not the language of education' (Mufanechiya \& Mufanechiya, 2011, p. 196) then a negative attitude develops towards mother tongue as a medium of instruction. In addition, Ndamba (2008) provides an example of an English honours degree having higher status than an honours degree in mother tongue. Further, Ndamba points out that underperformance in mathematics is due not only to learners' lack of mathematical knowledge but also to their incompetence in the language of instruction.

Given the lack of emphasis in the literature on issues of teaching and learning of mathematics in the FP, this study explored the experiences of FP PGCE pre-service teachers who completed the numeracy education module that was taught through the medium of isiZulu in 2011. The research question that guided this study was: What were FP PGCE pre-service teachers' experiences of being taught a numeracy education module through the medium of isiZulu? The article first discusses the theoretical framework provided by Lesh, Post and Behr (1987). Secondly, the methodology used in the study is presented, and thirdly we discuss the findings and present our conclusions.

1.In South Africa, the school subject 'Mathematics' was changed to 'Numeracy' in the FP with the introduction of Outcomes-Based Education in 1998. In2011, with the FP with the introduction of Outcomes-Based Education in 1998. In2011, with the
launch of the Curriculum and Assessment Policy Statement (DOE, 2011), 'Numeracy' launch of the Curriculum and Ass'
was renamed as 'Mathematics'.

\section{Theoretical framework}

An important aspect of any lecture or school classroom setting is the social interaction that occurs between the students or learners and the lecturer or teacher (Vygotsky, 1978). Although the interactions are through speaking, hearing and gestures, the interchange of knowledge, skills, attitudes and values in lecture rooms is also through symbolic, socially defined language norms. Mathematics is considered to be a language on its own (Usiskin, 1996). The South African Foundation Phase (Grade R-3) national curriculum statement lists specific skills that school learners need to develop in mathematics, including: 'Develop the correct use of the language of Mathematics'; 'Learn to listen, communicate, think, reason logically and apply the mathematical knowledge gained'; 'Learn to pose and solve problems'; and 'Build an awareness of the important role Mathematical plays in real life situations including the personal development of the learner' (DOE, 2011, pp. 8-9). Thus, the national curriculum statement emphasises that mathematics is yet another language that learners need to contend with in the classroom. Moreover, one of the core functions of mathematics is seen as facilitating problem solving, which requires additional knowledge, skills and attitudes on top of everyday spoken language knowledge. How are learners assisted to negotiate the language of mathematics and the language of instruction?

Lesh et al.'s work (1987) on language in the teaching and learning of mathematics is a relevant lens through which to explore our research question. The seminal work of Lesh et al. offers transformations that enhance mathematics development and promote problem-solving ability. These authors distinguish five types of representation necessary in mathematics learning:

(1) ... knowledge is organized around 'real world' events that serve as general contexts for interpreting and solving other kinds of problem situations; (2) Manipulatable models ... in which the 'elements' in the system have little meaning per se, but the 'built in' relationships and operations fit many everyday situations; (3) pictures or diagrams - static figural models that, like manipulatable models can be internalized as 'images'; (4) spoken languages - including specialized sublanguages related to domains like logic, etc.; (5) written symbols - which, like spoken languages, can involve specialized sentences and phrases ... as well as normal English sentences and phrases. (p. 33)

The connections between representations are presented diagrammatically in Figure 1.

Lesh et al. (1987) argue that there are valuable ways of translating between and transforming within the five representations that are important in mathematical learning and developing problem-solving ability. In Figure 1 the double-headed arrows within each of the five representations indicate transformations, whilst those outside the five representations denote translations. Even though all of the representations are important in the teaching of mathematics - use of real life contexts, manipulatives, pictures, written symbols and verbal symbols - we concentrate on the latter 
because the four other representations are not relevant for analysing the data generated for this article. We pay attention to the FP PGCE pre-service teachers' experiences during the transformations within the verbal symbols representation. In particular, we look at the verbal symbols transformed through code-switching during lectures, translation of learning materials into different languages and communication with learners and teachers during professional practice at schools.

\section{Methodology}

The methodology employed is a qualitative case study of FP PGCE pre-service teachers who completed a numeracy education module that was offered through the medium of isiZulu in 2011. To explore the pre-service teachers' experiences, we worked in an interpretive paradigm. The experiences presented in this article are our interpretations (McNiff \& Whitehead, 2006). When conducting this research, we had 'insider and outsider' (Cohen, Manion \& Morrison, 2011) perspectives. We were 'insiders' by conducting research at our own HEI. At the same time, we were 'outsiders' since we were not the numeracy education module presenters. This allowed for confidence in our data as it was 'buttressed' (Miles \& Huberman, 1994) by the fact that we collected data in locations where we teach and research. We acknowledge that this analysis of qualitative data is further influenced by the fact that we lecture in mathematics education modules through the medium of English whilst our home languages are not English. We have taught mathematics education for more than 20 years through the medium of English to students whose mother tongue is also not English. We are interested in issues related to teaching through a second language.

The FP PGCE pre-service teachers, from two different campuses at our university, were invited to take part in the focus group discussions. At the time of data collection there were 58 students registered for the numeracy education module at both campuses. Twenty-four were registered at Campus A and 34 at Campus B. Of the 24 registered in Campus A, 8 attended the module in isiZulu and the remainder in English. Of the 34 registered at Campus B, 17 attended the module in isiZulu and the remainder in English. The participants were selected purposefully from the PGCE FP pre-service teachers registered in 2011 who completed the numeracy education module in isiZulu because we were interested in their experiences. All of the pre-service teachers who were registered for the module offered in isiZulu were invited to take part in the focus group discussions but only 25 volunteered to take part in the discussions. Table 1 shows the number of PGCE FP pre-service teachers registered for the isiZulu medium numeracy education module in 2011 at the two campuses and those who participated in the study.

The participants completed undergraduate degrees through the medium of English at a South African HEI. Thereafter they registered to study numeracy, life skills and literacy education in a FP PGCE programme through the medium of isiZulu because isiZulu is their mother tongue.

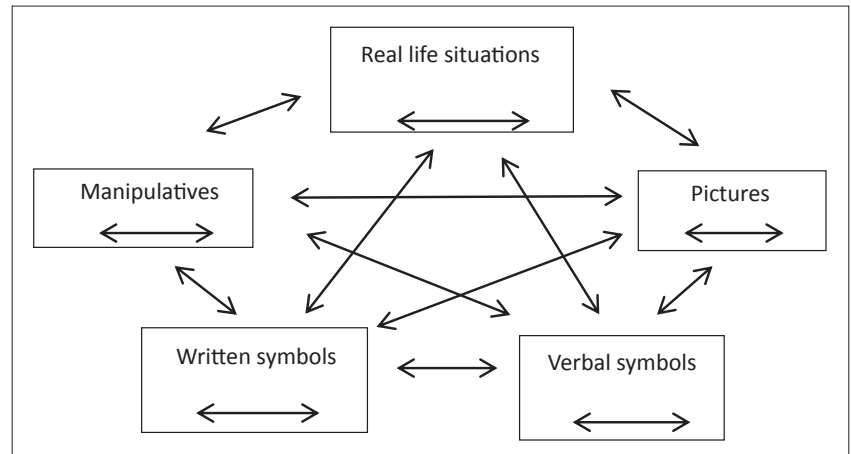

Source: Adapted from Lesh, R., Post, T., \& Behr, M. (1987). Representations and translations among representation in mathematics learning and problem solving. In C. Janvier (Ed.) Problems of representation in the teaching and learning of mathematics (pp. 33-40) Hillsdale, NJ: Lawrence Erlbaum

FIGURE 1: A diagrammatic representation of the translation model.

TABLE 1: The number of PGCE pre-service teachers registered for the isizulu numeracy education module and the number of participants in this study.

\begin{tabular}{llll}
\hline Campus & $\begin{array}{l}\text { Number of students in } \\
\text { numeracy education } \\
\text { module (both English } \\
\text { and isizulu) }\end{array}$ & $\begin{array}{l}\text { Number of students } \\
\text { in isizulu medium } \\
\text { numeracy education } \\
\text { module }\end{array}$ & $\begin{array}{l}\text { Number of } \\
\text { participants }\end{array}$ \\
\hline Campus A & 24 & 8 & 6 (75\% of cohort) \\
Campus B & 34 & 17 & 10 (59\% of cohort) \\
\hline
\end{tabular}

PGCE, Postgraduate Certificate in Education.

Before the relevant data were collected, all of the university's ethical clearance requirements were met. Written consent was requested and all 16 participants willingly signed the consent form that clearly stated that their responses were to be used for research purposes. The information provided was not related to sensitive issues, but we decided not to link responses to the real names of particular participants.

We conducted one focus group discussion at each campus with the PGCE pre-service teachers registered at the respective campus. The discussion focus was on these preservice teachers' experiences after having attended the numeracy education module offered in isiZulu. During the focus group discussions we used unstructured group discussions to encourage the pre-service teachers to share their experiences. The focus group discussions were transcribed verbatim and, where necessary, translated from isizulu into English. We were guided by the research question and the selected theoretical framework to inductively look for 'emerging patterns, associations, concepts and explanations' (Nieuwenhuis, 2010, p. 107). The 'describe, compare, relate' method described by Bazeley (2009) was used to elaborate on the analysis findings. After the data was inductively analysed, four areas emerged that relate to the presentation of the module in isiZulu: communication in isiZulu during lectures, academic concepts and isiZulu vocabulary, translation of teaching and learning materials, and status of the numeracy education module taught in isiZulu.

\section{Findings and discussion}

Each of the four areas that emerged from the findings is discussed under a separate subheading. The discussions are based on the participants' responses and are explained and illustrated using selected responses. In the excerpts, students 
are identified by campus, Campus A or Campus B, and then by a unique number in the particular campus group (e.g. Student B3).

\section{Communication in isizulu during lectures}

All of the participants indicated that the PGCE numeracy education module was taught largely in isiZulu, with minor switching from isiZulu to English where there was no isiZulu meaning for the mathematics education concepts being discussed. For them it was helpful that the module was taught in their mother tongue; they could follow the lecture easily and they enjoyed being taught in isiZulu. Two example responses are:

Student B1: It becomes easy when someone teaches you in isiZulu; you do not have to think what the person is saying, sometimes they do not have to even finish the sentence, you just get them.

Student B2: Even what the lecturer teaches, it was simplified and it stayed in you [sic]. I haven't studied it but I still remember how a child in a certain stage would approach a sum. So it was very helpful - numeracy is enjoyable in isiZulu.

Communication is at the centre of concept development (Vygotsky, 1978). This means that the participants were probably more at ease doing mathematics education through the medium of isiZulu which is their mother tongue. As students point out, they could anticipate and remember the concept development because it was conveyed in their mother tongue. Development and supplementation of the participants' existing knowledge in mathematics education was in a language medium in which the students felt confident.

\section{Academic concepts and isizulu vocabulary}

Although the participants appreciated that the module was taught in isiZulu, they experienced some constraints in using mathematics education concepts in isiZulu. They found that there was insufficient isiZulu vocabulary for the required concepts explored in the module. IsiZulu was limiting because the emphasis was on describing rather than in-depth theorising of numeracy education in relation to teaching and learning. For example:

Student B2: I think the isiZulu vocabulary needs a lot of additions.

Student A3: Learning using only isiZulu has challenges. For example, when explaining Vygotsky's Theory we would say: 'iqhaza likathisha ukuqinisekisa kulokhu abantwana abakwaziyo' [the teacher's responsibility is to build on what the learners already $k n o w], \ldots$ in English you can explain more fully ... ZPD and scaffolding ... in a test, but trying to explain these concepts in isiZulu you would get confused and not sure whether you are repeating yourself.

The above responses indicate that the pre-service teachers consider isiZulu vocabulary to be limited when it comes to exploring the academic concepts of teaching numeracy. For example, concepts such as the zone of proximal development (Vygotsky, 1978) are relevant for numeracy education. Student A3 pointed out that he understood the difference between the zone of proximal development and scaffolding. However, when he tried to define these concepts in isiZulu, he could not easily distinguish between them: he found the concepts difficult to explain in isiZulu. Similar feelings were expressed by other participants who experienced difficulty in formulating the meanings of theories and terms in isiZulu and mentioned that academic terminology is difficult to translate into isiZulu.

In addition, the pre-service teachers pointed out that the correct number names used in isiZulu are unfamiliar to school learners. Furthermore, the participants themselves seldom use the isiZulu number names for counting, as in everyday life they count in English. As a result, studying a numeracy module in isiZulu was difficult because the isiZulu spoken by participants is often mixed with English words. Student B1 commented on her experience whilst completing her professional practice teaching at a FP school:

Student B1: What I noticed about teaching numeracy in isiZulu and how you pronounce the numbers in isiZulu, for example 'isishiyagalombili' [eight], you find that learners are not used to those words ... even us as teachers. ... Even when you are teaching the learners, you find that the learners are more used to the English words when referring to numbers.

Mathematical language building and subsequent numeracy education concept development requires communication of concepts. However, the participants were required to work within both English and isiZulu. Here participants had to contend not only with the unfamiliar sound of terms in numeracy education, but also with the fact that their own understandings might be difficult to communicate because of the use of different languages. The meanings of the words the participants were required to use in developing appropriate mathematics education knowledge had to filter through thought, language and experience in two different languages, but only one language was allowed as a means of communication.

\section{Translation of teaching and learning materials}

Another challenge noted by the participants is the translation of materials, literature and assessment tasks. The course materials provided for the numeracy education module were mostly in English, with isiZulu notes prepared by the lecturer and distributed during lectures. However, the preservice teachers often needed to consult literature in the library, where all the articles and readings were in English. Translation of this literature was time-consuming and difficult because of insufficient vocabulary in isiZulu. For example:

Student B9: Although we do get notes in isiZulu but you find that some course packs are written in English, for example, when one has to do an assignment, you will have to start by translating the information.... Sometimes in that process you lose the meaning 
and you find that you end up not understanding what you wanted to say. ... When you have to study for the test, most of the materials are given to us in isiZulu but because we also have to refer to books written in English and you have to translate even the title.... So that is the challenge we often come across.

As mentioned before, the PCGE pre-service teachers completed their undergraduate degrees in HEIs where the instruction medium is English. The participants commented on the fact that they found it challenging to complete assessments in isiZulu as they have not studied in isiZulu for a long time. The following comments further illustrate the difficulties experienced:

Student A3: We got used to study in English from our first degrees and now we are forced to change to isiZulu and so the words are sometimes difficult. ... When we are writing tests and assignments it is so difficult, translating English to isiZulu.

Student A2: We find it hard to write in isiZulu because it has been a very long time since we last wrote in isiZulu.

The above responses signal the difference between spoken and written language. Cummins (1980) and Lim and Presmeg (2011) support this assertion, pointing out that there is a difference between basic interpersonal communicative skills and academic language proficiency. This means that the above participants' language competency in isiZulu was not sufficiently developed to ensure proficiency in academic language. As a result, they experienced difficult in writing tests and assignments in isiZulu.

The materials used in the numeracy education module were written in English and some were translated into isiZulu as lecture notes. However, the participants were of the opinion that the translated notes lacked depth and were mere summaries. Student B10 and Student B4 also mentioned the disadvantage that isiZulu materials were not provided timeously:

Student B10: We shouldn't receive the English course packs before the isiZulu course packs.

In addition to the materials in English and isiZulu not being provided simultaneously, the quality of the translations and the manner in which the translations were presented were also questioned by the participants:

Student B4: There should be more people translating materials from English to isiZulu. ... There should be more readings written in isiZulu so that we can learn successfully in isiZulu. ... We should not take people who are not isiZulu speakers and allow them to translate materials.

Student A2: I think the notes that we have in isiZulu are summaries because they are in point form.

However, not all participants noted negative experiences related to the learning materials. Student A3 felt that the availability of module materials in both English and isiZulu was an advantage to isiZulu-speaking pre-service teachers. They could read both sets of module materials to check their understanding of the concepts:
Student A3: If the materials could be isiZulu only we wouldn't be able to understand because there are some words we do not know in the language. Using only the English language also poses the same problems. Having both languages helps, it's just that there is a lot of work.

Assessment is an integral part of teaching and learning and has to match the mode of delivery of the module. The tests and examination papers were printed in both English and isiZulu for lecturers' convenience as the isiZulu students sat in the same venue as other PGCE pre-service teachers who were registered for the identical numeracy education module that was presented through the medium of English. At different times in the timetable, the same lecturer taught the numeracy education module in isiZulu or in English. Some participants found the use of both languages in the tests confusing, whilst others found this beneficial:

Student A3: Writing becomes easier in English while you would need to give yourself lots of time analysing a test written in isiZulu so that you can understand it. It's just that it would be good if we would only have tests written in isiZulu.

Interviewer: So, in other words, you are saying, using isiZulu and English simultaneously in the tests, caused the confusion.

Student A5: I tend to differ; I ... would read a paragraph in isiZulu without getting any meaning. Then I go back to English; it is only then I am able to understand what is going [on].

As well as the benefits or problems of writing tests and examination papers provided in both languages, participants pointed out that there were problems with completing tests within the specified time limits. The time constraints during tests and examinations meant that the participants did not have sufficient time to translate and write 'proper' isiZulu. They tended to mix isiZulu with English when they could not immediately think of the correct or appropriate isiZulu concept. As a consequence, the participants were penalised for including English words in the tests or examination instead of using only isiZulu:

Student B5: I am worried about the test because ... I did not know that I had to write in isiZulu but I wrote most of the things in isiZulu which makes me worry about the exam. $[\mathrm{In}]$ the exam I would be mixing isiZulu with English and I don't know if [examiners] will mark it or not because we don't have much material [provided in isiZulu] which allow us to write in isiZulu.

Another participant highlighted the fact that translation into isiZulu is time consuming:

Student B2: Also it takes us more time to get to the point as opposed to our counterparts writing in English, sometimes you would find that they have finished writing but we haven't because it is harder to fully explain a concept in isiZulu and also the people who are marking expect you to write in genuine isiZulu.

Contrary to the tests or examinations written in both languages, the assignment was provided only in isiZulu 
for the pre-service teachers who were registered for the numeracy education module offered in isiZulu. However, the participants were required to read and understand the literature in English and translate the information before submitting the assignment. The process of writing the assignment thus took much longer for the pre-service teachers writing in isiZulu. Computer word processors do not usually have spell check available in isiZulu so the participants checked for typographical errors manually. Consequently, they took longer to complete assignments than the pre-service teachers who submitted their assignments in English as word processors have English spell-checking facilities. The students' experiences expressed below reiterate Cummins's (1980) distinction between basic interpersonal communicative skills and academic language proficiency:

Student A2: When we are writing assignments we end up having to ask other people for translations of certain English words, not that we forget, we know it because it is a simple language, we know the basics but in terms of writing academically, it's difficult.

Student A1: What I do when I am writing my assignments; when I start to realise that I'm starting to fail getting the message across in isiZulu, I write an English word in brackets.

Student A7: It puts strain on me when I have to start reading the literature in English, translate to isiZulu, you know, it becomes a lot of work. ... [Rather], read in English, understand in English, write in English and type in English.

In the translation model developed by Lesh et al. (1987), one of the five representations necessary for ensuring mathematical concept development in learners is 'verbal symbols'. This model was designed by these authors for consideration in the development of mathematics and numeracy education. If more than one language is used in mathematics education then transformations within the verbal symbol representation become complicated. This occurs because verbal symbol translations, as described in Lesh et al.'s model, are usually considered to occur within a single spoken language. However, when translation between two languages, such as isiZulu and English, are necessary then the verbal symbol representation will require additional translations: within each of the two languages and between the two languages. The single verbal symbol representation presented in Lesh et al.'s model requires adaptation to show two different sets of verbal symbols.

Figure 2 shows how this adaptation in verbal symbol transformation may be represented diagrammatically. The figure shows the two sets of verbal symbols that the preservice teachers engaged in during the numeracy education module. The participants noted that the language used for numeracy education concepts in English is not sufficiently supported by equivalent academic language in isiZulu. The participants thus found conversion between the two sets of verbal symbols challenging and time consuming. Furthermore, the translations of materials were mainly from English into isiZulu: the students were often required to read and understand learning materials related to

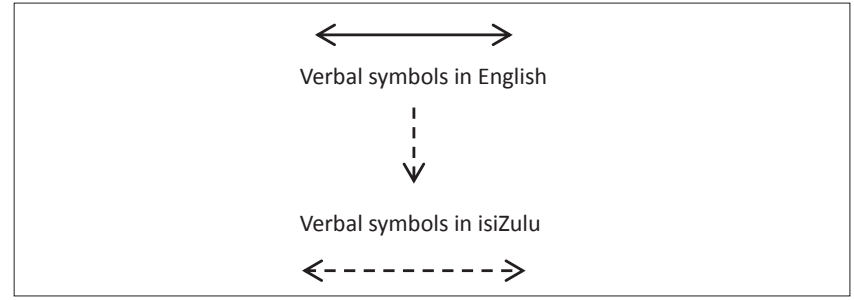

Source: Adapted from Lesh, R., Post, T., \& Behr, M. (1987). Representations and translations among representation in mathematics learning and problem solving. In C. Janvier (Ed.), Problems of representation in the teaching and learning of mathematics (pp. 33-40). Hillsdale, NJ: Lawrence Erlbaum

FIGURE 2: Diagrammatic representation of verbal symbols.

numeracy education in English and then to translate their understandings into isiZulu. The translations were problematic because of the technical and theoretical terminology in numeracy education. This means that the double-headed arrow between and within the two sets of verbal symbols in an ideal situation could not be achieved, and so broken-line arrows represent the existing, limited, incomplete translations of academic concepts.

The challenges experienced by the pre-service teachers are not only as a result of the difficulties experienced in translation, but also with the lower status ascribed to isiZulu as a medium of instruction by their peers and practising teachers.

\section{Status of the numeracy education module taught in isizulu}

According to the participants, not only does isiZulu have insufficient academic vocabulary for concepts taught in the numeracy education module, but it also has lower status. Those registered for this module noticed that their peers and practising FP teachers considered this module, delivered through the medium of isiZulu, to be inferior to and of lower status than the equivalent FP numeracy education module offered in English:

Student A2: Basically people look down upon us because we are learning in isiZulu. They tend to think that our qualification is not the same as the one for those learning in English.

Interviewer: How do you take your peers' comments?

Student A1: Personally since I understand the reason behind us learning in isiZulu ... is because of the child's interest. I am not offended. But to someone who does not understand ... to him/her we are just playing games.

Student A2: They say we are crèche teachers.

The difficulty faced by the pre-service teachers taking the numeracy module in isiZulu was that their peers, who were studying the same module in English, considered them inferior and labelled them as 'crèche teachers'. Although the pre-service teachers were all studying identical numeracy education module content and FP PGCE qualification, nonetheless they were considered to be teachers of 'nursery school', where no serious teaching and learning takes place. The implication is that FP PGCE teachers will only be care givers, instead of teachers, of young learners. However, 
some participants studying in isiZulu did not take offence: they understood the need to study in isiZulu, as this would eventually benefit isiZulu mother tongue learners. Despite the benefits of mother tongue instruction, negative attitudes towards its use as the language of instruction persist. Similar concerns were expressed in the research findings of Ndamba (2008): African students considered a degree in English to be more prestigious than a degree in an African language. The lower status accorded to mother tongue instruction is often a result of English being the lingua franca in Africa.

According to policy documents, the official language of instruction at the majority of KwaZulu-Natal FP schools should be isiZulu. However, the participants were pressured by school mentors during professional practice to use English rather than isiZulu when teaching mathematics. The mentors are practising FP teachers who oversee the preservice teachers' teaching during their professional practice at schools. The mentors were of the opinion that their FP learners would experience language difficulties if the FP mathematics lessons were conducted through the medium of isiZulu. In Grade 4, the medium of instruction is usually English in KwaZulu-Natal, so the teachers prefer to teach FP mathematics also through the medium of English, despite this being against official national policy imperatives:

Student B7: In the school that I was in, the principal said 'Don't teach in isiZulu too much because they sometimes get lost', so we ended up having to add some English.

Student B6: I found it to be a bit challenging. ... My mentor teacher was speaking a lot of English in class, did everything in English. When I teach in isiZulu the learners did not have a problem learning in isiZulu, but the mentor teacher ... [said] if it happens that learners go to other schools they need to be able to speak English, [so that they are not] labelled as unsuccessful learners. [Also, I] explained to the mentor that the person coming to assess me expects me to teach in isiZulu, so it is important that I teach in isiZulu and learners get to understand better, ... using their home language.

The response of participant Student B6 clearly indicates that there is a mismatch between reality and what the university's language policy is attempting to achieve through taking cognisance of and initiating implementation of the Languages in Education Policy (DOE, 1997). Despite peers and practising FP teachers' poor perceptions of teaching of numeracy through the medium of isiZulu and their reluctance in taking up the recommendations of language policy documents in teaching and learning numeracy, the participants were generally positive about being instructed through this medium at their HEI.

\section{Conclusions}

Obviously it would be naïve to think that merely changing the medium of instruction in a pre-service teacher education module is sufficient to change the poor mathematics achievements of South African learners. There are many political, social and economic factors that also need to be addressed in the South African teaching and learning context. However, the participants' experiences described in this article give a clear indication that pre-service teachers are willing to teach young learners mathematics in their mother tongue.

The challenges communicated by the participants are generally connected to technical delivery issues that were experienced during the isiZulu numeracy education module. The resolution of these issues does not seem insurmountable. For example, it should be possible to develop isiZulu technical and theoretical terminology that is acceptable, appropriate and correct for use in numeracy education teaching and learning. There are a number of names for counting in isiZulu, but there are many other terms and concepts that need to be 'created' to enhance numeracy education development through the medium of isiZulu. In other words, the verbal symbols in isiZulu that relate to numeracy education require formalisation, acceptance and usage by isiZulu academia, particularly in the area of mathematics education, as well as by the larger Zulu-speaking community. In addition, if our university is sincere about achieving its strategic goal to promote multilingualism, then it should establish a centre dedicated to assisting academics in translating learning materials.

However, one of the most challenging issues relates to the status of modules presented through the medium of isiZulu. In South Africa, English is considered to be important for economic, political, social and educational betterment. This leads to English being afforded a higher status than the other 10 South African official languages. This influences members of the teaching community, as well as of the community at large, to believe that teaching and learning through English is 'better'. Moreover, parents may consider that the benefits of learning to speak English fluently from a young age far outweigh the benefits of being taught in mother tongue. It will thus be difficult, but necessary, to convince learners, teachers and parent communities that providing opportunities for mother tongue instruction in mathematics is significant. Furthermore, to initiate mother tongue instruction at higher education institutions, each institution needs to start by using a 'bottom-up' approach within their community to elevate the status of mother tongue instruction. For example, instead of translating teaching materials from English or Afrikaans into a mother tongue, academics at the higher education institution could develop their own authentic mother tongue teaching material. This is particularly important for FP pre-service teachers who are being prepared to teach young learners in their mother tongue. Improving the status of mother tongue instruction within a higher education institution is the first important step in dispelling the impression that teaching FP PGCE students numeracy education in their mother tongue results in preparing merely 'crèche teachers'.

\section{Acknowledgements}

We thank the Department of Higher Education and Training and the European Union for funding the Primary Education 
Sector Policy Support programme from which the data for this article comes. Our views are expressed in this article.

\section{Competing interests}

We declare that we have no financial or any other competing interests that might prevent us from executing and publishing unbiased research.

\section{Authors' contributions}

L.V.L. (University of KwaZulu-Natal) and B.G. (University of KwaZulu-Natal) were equally responsible for conducting all the research and preparing the manuscript.

\section{References}

Adler, J. (1998). A language of teaching dilemmas: Unlocking the complex multilingual secondary mathematics classroom. For the Learning of Mathematics 18(1), 24-33.

Adler, J., \&. Setati. M. (2000). Between languages and discourses: Language practices in primary multilingual mathematics classrooms in South Africa. Educational Studies in Mathematics, 43(3), 243-269. http://dx.doi.org/10.1023/A:1011996002062

Alexander, N. (2000). English unassailable but unattainable: The dilemma of language policy in South African education. Occasional Paper 3. Cape Town: Project for the policy in South African education. Occasional Paper 3. Cape Town: Project for the Study of Alternative Education in South Africa (PRAESA). Available from http:// www.praesa.org.za/occasional-paper-3-english-unassailab
the-dilemma-of-language-policy-in-south-african-education/

Alexander, N. (2009, May). Mother tongue bilingual teaching is the key. Pape presented at the colloquium on mother tongue teaching in the early years. presented at the colloquium on moth
University of KwaZulu-Natal, Durban.

Bazeley, P. (2009). Analysing qualitative data: More than 'identifying themes'. Malaysian Journal of Qualitative Research, 2, 6-22.

Chen, X., \& Li, Y. (2008). Language proficiency and mathematics learning. School Science and Mathematics, 108(3), 90-93. http://dx.doi.org/10.1111/j.1949-8594.2008. tb17811.x

Cohen, L., Manion, L., \& Morrison, K. (Eds.). (2011). Research methods in education (7th edn.). London: Routledge.

Cummins, J. (1980). The entry and exit fallacy in bilingual education. In C. Baker, \& N.H. Hornberger (Eds.), An introductory reader to the writings of Jim Cummin (pp. 110-138). Clevedon: Multilingual Matters.

Cummins, J. (1981). Bilingualism and minority: Language children. Toronto: OISE Press.

Department of Education. (1997). Language in education policy. Pretoria: DOE

Department of Education. (2002). Language policy for higher education. Pretoria: DOE

Department of Basic Education. (2011). Curriculum and assessment policy statement. Foundation Phase Grades 1-3. Pretoria: DBE. Available from http://www. education.gov.za/LinkClick.aspx?fileticket=ehGEpQZXz7M\%3d\&tabid=671\&m id $=1880$

Desai, Z.K. (2012). A case for mother tongue education? Unpublished doctoral dissertation. University of the Western Cape, Cape Town, South Africa.

Essien, A.A. (2010). Investigating proficiency in the language of instruction as means of improving mathematical proficiency in a multilingual classroom. Education as Change, 14(2), 169185. http://dx.doi.org/10.1080/16823206.2010.518006

Green, W., Parker, D., Deacon, R., \& Hall, G. (2011). Foundation Phase teache provision by public higher education institutions in South Africa. South African Journal of Childhood Education, 1(1), 109-122. Available from http://www.uj.ac.za/EN/Faculties/edu/CentresandInstitutes/UJICE/ SouthAfricanJournalofChildhoodEducation/Documents/SAJCE e-version\%20 vol\%201(1).pdf
Howie, S.J. (2002). English language proficiency and contextual factors influencing mathematics achievement of secondary pupils in South Africa. Unpublished doctoral dissertation. University of Twente, Enschede, The Netherlands. Available from http://doc.utwente.nl/68213/

Kajoro, P., \& Halai, A. (2012, July). Transition of the medium of instruction from English to Kiswahili in primary schools: Experiences from the Tanzanian mathematics classrooms. Paper presented at the 12th International Congress on Mathematical Education. Coex, Seoul.

Lesh, R., Post, T., \& Behr, M. (1987). Representations and translations among representation in mathematics learning and problem solving. In C. Janvier (Ed.), Problems of representation in the teaching and learning of mathematics (pp. 3340). Hillsdale, NJ: Lawrence Erlbaum.

Lim, C.S., \& Presmeg, N. (2011). Teaching mathematics in two languages: A teaching dilemma of Malaysian Chinese primary schools. International Journal of Science and Mathematics Education, 9, 137-161. http://dx.doi.org/10.1007/s10763-0109225-4

Mashiya, N. (2010). Mother tongue teaching at the University of KwaZulu-Natal: Opportunities and threats. Alternation, 17(1), 92-107. Available from http:// alternation.ukzn.ac.za/docs/17.1/05\%20Mas\%20FIN.pdf

Mashiya, N. (2011). IsiZulu and English in KwaZulu-Natal rural schools: How teachers fear failure and opt for English. South African Journal of Childhood Education, 1(1), 19-31. Available from http://www.uj.ac.za/EN/Faculties/ edu/CentresandInstitutes/CEPR/SouthAfricanJournalofChildhoodEducation/ Documents/SAJCE_e-version\%20vol\%201(1).pdf

McNiff, J., \& Whitehead, J. (2006). All you need to know about action research. London, Sage. PMCid:2794634

Miles M.B., \& Huberman, A.M. (1994). An expanded sourcebook: Qualitative data analysis. (2nd edn.). London: Sage.

Mufanechiya, A., \& Mufanechiya, T. (2011). Using mother tongue as a medium of instruction in the teaching of mathematics in the Zimbabwean junior primary schools: Desirable or feasible? Journal of Asian Scientific Research, 1(4), 194-203. Available from http://econpapers.repec.org/article/asijoasrj/

Ndamba, G.T. (2008). Mother tongue usage in learning: An examination of language preferences in Zimbabwe. The Journal of Pan African Studies, 2(4), 171-188.

Nieuwenhuis, J. (2010). Analysing qualitative data. In K. Maree (Ed.), First steps in research (pp. 98-122). Pretoria: Van Schaik Publishers.

Setati, M. (1998). Innovative language practices in multilingual mathematics classrooms. Johannesburg: Joint Education Trust. Available from http://www. jet.org.za/publications/pei-research/001734\%20Setati\%20Innovative\%20 jet.org.za/publications/p

Setati, M. (2008). Access to mathematics versus access to the language of power: The struggle in multilingual mathematics classrooms. South African Journal of Education, 28(1), 103-116. Available from http://www.sajournalofeducation. Education, 28(1), 103-116. Available from
co.za/index.php/saje/article/view/150/99

Skutnabb-Kangas, T. (2009, January). The stakes: Linguistic diversity, linguistic human rights and mother tongue based multilingual education or linguistic genocide, crimes against humanity and even faster destruction of biodiversity and our planet. Keynote presentation at Bamako International Forum on Multilingualism. Bamako, Mali. Available from http://www.tove-skutnabb-kangas.org/pdf/Tove_ Skutnabb_Kangas_Keynote_presentation_at_Bamako_International_Forum_on Multilingualism_Bamako_Mali_19_21_Jan_2009.pdf

University of KwaZulu-Natal. (2006). University of KwaZulu-Natal language policy. Available from http://utlo.ukzn.ac.za/Libraries/November 2011 Conferences/ APPENDIX_D4_Language_Policy___Council_approved_010906.sflb.ashx

University of KwaZulu-Natal. (2013). University of KwaZulu-Natal strategic plan $2007-$ 2016. Available from http://www.ukzn.ac.za/aboutus/strategicplan.pdf

Usiskin, Z. (1996). Mathematics as a language. In P. Elliott, \& M.J. Kenney (Eds.), National Council of Teachers of Mathematics Yearbook (pp. 231-243). Reston, VA: NCTM.

Vandeyar, S. (2010). Assessing Grade 4 mathematics in the learner's mother tongue: A South African experiment. Early Child Development and Care, 180, 921-929. http://dx.doi.org/10.1080/03004430802548155

Vygotsky, L.S. (1978). Mind in society: The development of higher psychological processes. Cambridge, MA: Harvard University Press. 